\title{
Factors Associated with Numbers of Antenatal Care Visits in Rural Ethiopia
}

\author{
Melkalem Mamuye Azanaw (iD) \\ Alemayehu Digssie \\ Gebremariam (iD) \\ Fentaw Teshome Dagnaw (D) ${ }^{\prime}$ \\ Hiwot Yisak (D) \\ Getaneh Atikilt ${ }^{\prime}$ \\ Binyam Minuye iD ${ }^{2}$ \\ Melaku Tadege Engidaw (D) \\ Desalegn Tesfa (iD \\ Edgeit Abebe Zewde (iD ${ }^{3}$ \\ Sofonyas Abebaw Tiruneh (D) \\ 'Department of Public Health, College of \\ Health Sciences, Debre Tabor University, \\ Debre Tabor, Ethiopia; ${ }^{2}$ Department of \\ Nursing, College of Health Sciences, \\ Debre Tabor University, Debre Tabor, \\ Ethiopia; ${ }^{3}$ Department of Biomedical \\ Sciences, College of Health Sciences, \\ Debre Tabor University, Debre Tabor, \\ Ethiopia
}

Correspondence: Melkalem Mamuye Azanaw

Email Melkalem21@gmail.com
Introduction: Antenatal care (ANC) is a medical care and procedure carried out for pregnant women. Data on ANC visits can help policymakers show gaps in service provision. Therefore, this study assessed the factors associated with the number of ANC visits among women in rural Ethiopia.

Methods: We included a total of 6611 women who gave birth within 5 years preceding the survey from the 2016 Ethiopian Demographic and Health Survey. A multi-level negative binomial regression analysis was employed to consider the hierarchical nature of the data. In the multivariable analysis, variables with a p-value $<0.05$ were considered to be significantly associated with the number of ANC visits.

Results: Overall, 27.3\% (95\% CI: 14.63, 15.76) of women had at least four ANC visits during pregnancy in rural Ethiopia. Among individual level factors, age group 25-29 years (adjusted incidence rate ratio $(\mathrm{AIRR})=1.13,95 \% \mathrm{CI}: 1.02,1.26)$, household rich wealth status $\quad(A I R R=1.17,95 \% \quad C I: 1.04,1.31)$, women's educational status (primary, $\mathrm{AIRR}=1.19,95 \% \mathrm{CI}: 1.08,1.32$; secondary, $\mathrm{AIRR}=1.30,95 \% \mathrm{CI}: 1.08,1.55$; above secondary, $\mathrm{AIRR}=1.35,95 \% \mathrm{CI}: 1.07,1.71$ ), partner educational status (primary, AIRR=1.16, 95\% CI:1.05,1.28; secondary, AIRR $=1.22,95 \% \mathrm{CI}: 1.08,1.38$ ), and autonomy to decision to their care $(\mathrm{AIRR}=1.25,95 \% \mathrm{CI}: 1.10,1.42)$ were positively associated factors whereas having a birth order of five or more (AIRR $=0.80,95 \%$ CI: $0.69,0.94$ ) was a negative associated with number of ANC visits. Among community-level variables, being in higher community level literacy $(\mathrm{AIRR}=1.35,95 \% \mathrm{CI}: 1.14,1.59)$ and higher poverty level (AIRR=0.77, $95 \%$ CI: 0.64, 0.92) were significant factors with the number of ANC visits.

Conclusions and Recommendations: Women's age, wealth status, women's educational status, partner educational status, autonomy to decision making in health care, and birth order were determinants of the number of ANC visits. Furthermore, poverty and literacy are also important factors at the community level. Addressing economic and educational interventions for rural women should be prioritized.

Keywords: antenatal care, women, rural Ethiopia, multilevel negative binomial count analysis

\section{Introduction}

Antenatal care (ANC) is an umbrella term that describes medical care and procedures performed for pregnant women. ${ }^{1}$ It is the delivery of health care to pregnant women throughout their pregnancy. Services during ANC visits aimed at detecting the already existing problems and/or problems that might develop during pregnancy, which may affect the pregnant woman and/or her unborn child. ${ }^{2}$ Screening tests, diagnostic procedures, and prophylactic treatments are services provided to pregnant women based on identified problems and risk factors. ${ }^{3}$ 
The World Health Organization (WHO) recommends that all pregnant women and newborns receive quality care which means the extent of health care services provided to women to have the desired birth outcomes. Recommended activities to ensure the quality of care include nutritional interventions, maternal and fetal assessment, preventive measures, interventions for common physiological conditions, and health system interventions. ${ }^{4}$ ANC can save the lives of mothers and babies directly by reducing stillbirths and neonatal deaths and indirectly by promoting and establishing good health before childbirth and the early postnatal period. A previously published study indicated that if $90 \%$ of women received ANC, up to $14 \%$, or 160,000 more newborn lives, could be saved in Africa. Remarkably, ANC also helps to communicate and help women, families, and communities in a dangerous situation in a woman's life. ${ }^{5}$

Antenatal care service is one of the health services utilization that combat morbidity and mortality among pregnant mothers. Appropriate and recommended ANC services support safe maternity and delivery which ultimately improves maternal and child health through standard and special care. A pregnant woman may require special care and more visits depending on the setting since approximately $25-30 \%$ of the women have been with specific risk factors. ${ }^{6}$

Many efforts have been made to assess the evolution in coverage of antenatal care in developing countries that focused on issues such as the number of visits, the timing of visits, and the characteristics of users and non-users of antenatal $^{\text {care. }}{ }^{7}$

The number of antenatal care services is determined by socio-demographic characteristics and contextual factors. Regarding individual factors, higher educational status, older age, and higher income were positively associated with the number of antenatal care visits. On the other hand, fewer antenatal care visits were associated with parity, gestational age at delivery, time of initiation of ANC, and medical risks during the pregnancy. Concerning contextual factors; distance from a health facility, service waiting time, and client welcomed appreciation were associated with ANC service utilizations. In addition, women's knowledge regarding ANC, the presence of electricity in households, and housing conditions were associated with ANC service utilization. ${ }^{8-32}$

Although antenatal care is crucial, information on factors of the number of ANC in rural areas of Ethiopia is still very limited due to different reasons. A detailed investigation of factors affecting the number of ANC service utilization is crucial. Therefore, this study was conducted to analyze the number of ANC visits and its determinants among women who gave birth in the last five years preceding the survey in rural Ethiopia. Besides, this study provides valuable information on count data models.

\section{Methods}

\section{Study Area and Data Source}

The study was conducted in Ethiopia, which is located in the horn of Africa, between $3^{\circ}$ and $15^{\circ}$ North latitudes and $33^{\circ}$ and $48^{\circ}$ East longitudes. We used the EDHS 2016 dataset that was conducted by the Central Statistical Agency $^{33}$ in collaboration with the Federal Ministry of Health $(\mathrm{FMoH})$ and the Ethiopian Public Health Institute (EPHI). The Ethiopian DHS is conducted every 5 years to assess the population and health-related indicators of the country. Data were obtained from the DHS website (URL: www.dhsprogram.com) after contacting them via email through personal accounts and justifying the reason for requesting it.

\section{Population and Sampling Procedure}

The study was conducted using nationally representative data from the 2016 Ethiopian Demographic and Health Survey. The current study used 443 enumeration areas (EAs) from 645 EDHS EAs or clusters as identified by the 2007 Ethiopia Population census. A stratified twostage sampling procedure was employed to identify households from all eligible rural households within each cluster. The source population was women of reproductive age who gave birth within five years before the survey in rural Ethiopia. The study population included women of reproductive age who gave birth within five years before the survey in the households located in the primary sampling units (PSUs) in the 443 EAs sampled in the first stage.

\section{Variables}

The outcome variable was the number of ANC visits each participant had during the last pregnancy. Individual, household, community, and regional level variables were considered as explanatory variables. The individual-level explanatory variables included the education status of the women and their husbands, age of the women, the autonomy of the women to healthcare issues which means women's participation in the household to make a decision alone or jointly with their husbands in women's 
health care issues, women's and husbands' occupational status, birth order of a child, and household wealth status whereas community-level variables were regional settings, community-level poverty, and literacy.

\section{Data Processing and Analysis}

The data were cleaned using STATA version 16.0 software. The analysis was conducted after sample weights were applied for complex sampling procedures. The characteristics of the study participants were described using frequencies and percentages.

Let $Y_{i j}$ represents the number of ANC visits of the $i^{\text {th }}$ women living in the $j^{\text {th }}$ cluster, and the vector $X_{i j}$ to the corresponding values of the independent variables. Assuming independent women who are on ANC visits, Poisson regression and negative binomial regression models are specified as:

$$
\log \left(\mu_{i j}\right)=\beta_{0}+\beta X_{i j}
$$

where $\mu_{i j}$ is the expected number of ANC visits as a function of independent variables, $\beta_{0}$ the overall intercept, and $\beta$ the vector of regression coefficients. The assumed distribution of the number of ANC visits is the difference between the Poisson regression (PR) and the negative binomial regression model (NBR). In PR, the outcome variable is assumed to follow a Poisson distribution with $E\left(y_{i j}\right)=\mu_{i j}$ $=\operatorname{var}\left(y_{i j}\right)$, while in NBR, it is assumed to follow a negative binomial distribution with $\mathrm{E}\left(y_{i j}\right)=\mu_{i j}$ and $\operatorname{var}\left(y_{i j}\right)=\theta \mu_{i j}$, where $\theta$ is the shape parameter that controls the variance. When $\theta=1$, the NBR model becomes PR model without over-dispersion.

When the assumptions of independence are violated in clustered data, using PR and NBR models could lead to biased estimates and misinterpretation of the results. ${ }^{34}$ The best way to consider the non-independence of observations is to use multilevel models. The use of a multilevel modeling strategy accommodates the clustered or hierarchical nature of the EDHS data and adjusts standard errors of the estimated coefficients for ICC. A simple multilevel PR/ NBR model is obtained by incorporating cluster-specific random effects in the standard PR/NBR model:

$$
\log \left(\mu_{I J}\right)=\left(\beta_{0}+b_{0 j}\right)+\beta X_{i j}
$$

Where $b_{0 j}$ denotes the random intercepts at cluster level and are assumed to follow a normal distribution with constant variance. Therefore, the multilevel PR and NBR models are preferred to model the data. ${ }^{35}$
The random effects (variation of effects) were estimated by intracluster correlation coefficient (ICC) (variance partition coefficient) and the percentage change in variance (PCV). The ICC explains the cluster variability whereas PCV measures the total variation due to factors at the community and individual levels. The ICC and PCV were determined using the following formulas:

$$
\begin{aligned}
I C C= & \text { the variance of the null model } / \\
& (\text { variance of the null model }+3.29)
\end{aligned}
$$

$$
P C V=\frac{\left(\begin{array}{l}
\text { variance of the } \\
\text { initial model }
\end{array}-\begin{array}{l}
\text { variance of the model } \\
\text { with more terms }
\end{array}\right)}{* 100 \text { the variance of the initial model }}
$$

A multilevel model provides correct parameter estimates by adjusting the biases introduced from clustering to give correct SEs. Thus, it produces correct confidence interval and significance tests. ${ }^{36}$

The goodness of fit statistics by Pearson Chi-square of Poisson regression analysis was conducted to show whether over-dispersion is present or not. If the observed value of the Pearson Chi-square statistic divided by the degrees of freedom is higher than one, the mentioned goodness of statistics represents over-dispersion in the data set.

\section{Operational Definitions Number of Antenatal Care Visit}

Is the number of visit to receive prenatal care among women who gave birth five years preceding the survey, information was recorded for the last birth. ${ }^{37,38}$

\section{Community Women's Literacy}

Categorized into two as a higher proportion of women's literacy within the cluster and a lower proportion of women's literacy based on the median value. The aggregate of individual women's ability to read-only parts of a sentence, able to read the whole sentence, and no card with required language can show the overall literacy status of women within the cluster. ${ }^{39}$

\section{Community-Level Poverty}

Categorized into two as a higher proportion of poorest and poorer households within the cluster and lower poorest and poorer households based on the median value. The aggregate of individual women from the poorest and poorer households can show the overall community-level poverty of women within the cluster. ${ }^{39}$ 


\section{Results}

\section{Socio-Demographic Characteristics of}

\section{Respondents}

The total number of women was 6611 with mean $( \pm \mathrm{SD})$ ages of $29.7( \pm 7.4)$ years. About $3219(48.7 \%)$ women were between the age of 30 to 45 years. Approximately $70 \%$ of women were non-educated with $224(3.4 \%)$ secondary and above secondary school. Almost all (>94\%) of women were married. About 2916 (44.1\%) of women were from the Oromia region and 2596 (39.3\%) women were Muslim religion followers. Moreover, 3681 (55.7\%) of the women had no work. Regarding household wealth status, nearly half $(49.1 \%)$ of the women were from poor or poorest households whereas, 1803 (27.2\%) belonged to rich and richest households during the five years preceding the survey (Table 1).

\section{Community-Level, Maternal, and Health Service-Related Characteristics}

Approximately $74.0 \%$ of women had participated in a decision of their health care issues, 4240 (64.1\%) of them had big problems in distance to the health facility. Regarding birth order, 2037 (30.8\%) women had a child with above five birth order whereas, 1099 (16.6\%) had first birth order child (Table 2).

\section{Number of ANC Visits During Pregnancy}

The median and mode of the frequency of antenatal care visits were 2 and 0 among mothers who gave birth within the last five years respectively. Overall, 58.8\% (95\% CI: 57.6, 59.9) of women had at least one ANC visit during their pregnancy and only $27.3 \%$ (95\% CI: $14.63,15.76)$ of women had at least four times ANC visits during their pregnancy in rural Ethiopia.

\section{Factors Associated with Number of Antenatal Care Visits}

About $10.7 \%$ of the number of antenatal care visits during pregnancy in clusters was explained in the full model. The Percent change variation in the final model showed that about $74.9 \%$ of the total variability in the number of antenatal care visits was explained (Table 3).

Individual factors that had a significant association with the number of antenatal care visits were age, educational status of women, educational status of the husband, occupa-
Table I Sociodemographic Characteristics of Women Who Gave Birth Within the Last Five Years Preceding the Survey in Rural Ethiopia, EDHS 2016, 2020 (N=66II)

\begin{tabular}{|c|c|c|c|}
\hline Variables & Category & $\begin{array}{l}\text { Unweight } \\
\text { n (\%) }\end{array}$ & $\begin{array}{l}\text { Weighted } \\
\text { n (\%) }\end{array}$ \\
\hline Age in years & $\begin{array}{l}\text { Mean } \pm \text { SD } \\
15-24 \\
25-29 \\
30-49\end{array}$ & $\begin{array}{l}29.4 \pm 7.1 \\
1498(26.4) \\
1495(26.4) \\
2674(47.2)\end{array}$ & $\begin{array}{l}29.7 \pm 7.1 \\
1622(24.5) \\
1770(26.8) \\
3219(48.7)\end{array}$ \\
\hline Region & $\begin{array}{l}\text { Tigray } \\
\text { Afar } \\
\text { Amhara } \\
\text { Oromia } \\
\text { Somali } \\
\text { Benishangul } \\
\text { Gumz } \\
\text { SNNPR } \\
\text { Gambela } \\
\text { Harari } \\
\text { Dire Dawa }\end{array}$ & $\begin{array}{l}630(11.1) \\
571(10.1) \\
688(12.1) \\
968(17.1) \\
646(11.4) \\
536(9.5) \\
813(14.3) \\
393(6.9) \\
246(4.3) \\
176(3.1)\end{array}$ & $\begin{array}{l}438(6.6) \\
57(0.9) \\
1410(21.3) \\
2916(44.1) \\
226(3.4) \\
74(1.1) \\
1452(22.0) \\
12(0.2) \\
10(0.2) \\
16(0.2)\end{array}$ \\
\hline Religion & $\begin{array}{l}\text { Orthodox } \\
\text { Christian } \\
\text { Muslim } \\
\text { Protestant } \\
\text { Other }\end{array}$ & $\begin{array}{l}1650(29.1) \\
2753(48.6) \\
1122(19.8) \\
142(2.5)\end{array}$ & $\begin{array}{l}2332(35.3) \\
2596(39.3) \\
1463(22.1) \\
221(3.3)\end{array}$ \\
\hline $\begin{array}{l}\text { Educational status } \\
\text { of women }\end{array}$ & $\begin{array}{l}\text { No education } \\
\text { Primary } \\
\text { Secondary } \\
\text { Above }\end{array}$ & $\begin{array}{l}3973(70.1) \\
1423(25.1) \\
222(3.9) \\
49(0.9)\end{array}$ & $\begin{array}{l}4555(68.9) \\
1833(27.7) \\
191(2.9) \\
33(0.5)\end{array}$ \\
\hline $\begin{array}{l}\text { Educational status } \\
\text { of partner/husband }\end{array}$ & $\begin{array}{l}\text { No education } \\
\text { Primary } \\
\text { Secondary } \\
\text { Above } \\
\text { Do not know }\end{array}$ & $\begin{array}{l}2909(54.8) \\
1785(33.6) \\
387(7.3) \\
200(3.8) \\
32(0.6)\end{array}$ & $\begin{array}{l}3194(51.4) \\
2479(39.9) \\
382(6.1) \\
129(2.1) \\
33(0.5)\end{array}$ \\
\hline $\begin{array}{l}\text { Current marital } \\
\text { status }\end{array}$ & $\begin{array}{l}\text { Single/separated } \\
\text { Married/in union } \\
\text { Divorced/ } \\
\text { Widowed }\end{array}$ & $\begin{array}{l}8 I(I .4) \\
5313(93.8) \\
273(4.8)\end{array}$ & $\begin{array}{l}114(1.7) \\
6218(94.1) \\
279(4.2)\end{array}$ \\
\hline $\begin{array}{l}\text { Occupation status } \\
\text { of women }\end{array}$ & $\begin{array}{l}\text { No work } \\
\text { Agriculture } \\
\text { employee } \\
\text { Non agriculture } \\
\text { workers }\end{array}$ & $\begin{array}{l}3315(58.5) \\
1389(24.5) \\
963(17.0)\end{array}$ & $\begin{array}{l}368 \mid(55.7) \\
1706(25.8) \\
1225(\mid 8.5)\end{array}$ \\
\hline $\begin{array}{l}\text { Sex of household } \\
\text { head }\end{array}$ & $\begin{array}{l}\text { Female } \\
\text { Male }\end{array}$ & $\begin{array}{l}1100(19.4) \\
4567(80.6)\end{array}$ & $\begin{array}{l}87 I(I 3.2) \\
574 I(86.8)\end{array}$ \\
\hline $\begin{array}{l}\text { Household wealth } \\
\text { status }\end{array}$ & $\begin{array}{l}\text { Poor } \\
\text { Middle } \\
\text { Rich }\end{array}$ & $\begin{array}{l}3506(61.9) \\
993(17.5) \\
1168(20.6)\end{array}$ & $\begin{array}{l}3243(49.1) \\
1565(23.7) \\
1803(27.2)\end{array}$ \\
\hline Total & & $5667(100)$ & $6611(100)$ \\
\hline
\end{tabular}


Table 2 Maternal, Obstetric, and Health Service-Related Characteristics of Women Who Gave Birth Within the Last Five Years Preceding the Survey in Rural Ethiopia, EDHS 2016, 2020

\begin{tabular}{|c|c|c|c|}
\hline Variables & Category & $\begin{array}{l}\text { Unweight } \\
\text { n (\%) }\end{array}$ & $\begin{array}{l}\text { Weighted } \\
\text { n (\%) }\end{array}$ \\
\hline Family size & $\begin{array}{l}\text { Less than } \\
\text { five } \\
\text { Five to ten } \\
\text { Greater } \\
\text { than ten }\end{array}$ & $\begin{array}{l}257 \mid(45.4) \\
2929(51.6) \\
167(3.0)\end{array}$ & $\begin{array}{l}2962(44.8) \\
345 \mid(52.2) \\
197(3.0)\end{array}$ \\
\hline $\begin{array}{l}\text { Autonomy to the } \\
\text { decision of health care }\end{array}$ & $\begin{array}{l}\text { No } \\
\text { Yes }\end{array}$ & $\begin{array}{l}1524(26.9) \\
4143(73.1)\end{array}$ & $\begin{array}{l}|72|(26.0) \\
4890(74.0)\end{array}$ \\
\hline $\begin{array}{l}\text { Distance to the health } \\
\text { facility }\end{array}$ & $\begin{array}{l}\text { Not big } \\
\text { problem } \\
\text { Big problem }\end{array}$ & $\begin{array}{l}2189(38.6) \\
3478(61.4)\end{array}$ & $\begin{array}{l}2371 \text { (35.9) } \\
4240(64.1)\end{array}$ \\
\hline Birth order & $\begin{array}{l}\text { One } \\
\text { Two to five } \\
\text { Greater } \\
\text { than five }\end{array}$ & $\begin{array}{l}950(16.8) \\
2994(52.8) \\
1723(30.4)\end{array}$ & $\begin{array}{l}1099(16.6) \\
3475(52.6) \\
2037(30.8)\end{array}$ \\
\hline $\begin{array}{l}\text { Community-level } \\
\text { poverty }\end{array}$ & $\begin{array}{l}\text { Low } \\
\text { High }\end{array}$ & $\begin{array}{l}282 I(48.5) \\
299 I(5 I .5)\end{array}$ & $\begin{array}{l}46 \mid I(69.8) \\
1999(30.2)\end{array}$ \\
\hline $\begin{array}{l}\text { Community-level } \\
\text { literacy }\end{array}$ & $\begin{array}{l}\text { Low } \\
\text { High }\end{array}$ & $\begin{array}{l}2644(45.5) \\
3168(54.5)\end{array}$ & $\begin{array}{l}2452(37.1) \\
4159(62.9)\end{array}$ \\
\hline Total & & $5667(100)$ & $6611(100)$ \\
\hline
\end{tabular}

tional status of the women, household wealth status, women's participation for decision-making on healthcare issues, and birth order of child whereas, community-level literacy, and poverty determine the number of antenatal care visits at the community level (Table 3 ).

Women in the age group of 25 to 29 years had $13 \%$ more antenatal visits compared to women age 15-24 years (IRR: 1.13, 95\% CI: 1.02-1.26). Women who were attending primary, secondary, and above secondary education had more antenatal care visits compared to non-educated women (primary education; IRR: 1.16, $(95 \% \mathrm{CI}: 1.05$, 1.28), secondary IRR: 1.22 , (95\% CI: $1.08,1.38)$, and above IRR: 1.35, (95\% CI: 1.07, 1.71)). Partner with primary education and secondary had $16 \%$ and $22 \%$ more antenatal visits compared with a partner who had no educational status (IRR: 1.16, $(95 \%$ CI: $1.05,1.28)$ and IRR: 1.22, (95\% CI: 1.08, 1.38), respectively). Women from richer households had $17 \%$ more antenatal care visits compared with women from poorer households (IRR: 1.17 , (95\% CI: 1.04, 1.31). Women who had the decisionmaking power to their health care were $25 \%$ more antenatal care visits (IRR: 1.25, (95\% CI: 1.10, 1.42). On the other hand, women who had a higher birth order child had lower antenatal care visits compared to women who had first order child (IRR: $0.80,(95 \%$ CI: 0.69, 0.94).

Furthermore, community-level variables were significantly associated with the number of antenatal care visits after controlling the possible confounding by multivariate analysis. Women from higher literacy level communities had 35\% higher antenatal care visits (IRR: 1.35, (95\% CI: $1.14,1.59)$ whereas women from the higher poverty level community had 23\% lower antenatal care visits (IRR: 0.77 (95\% CI: 0.64, 0.92) (Table 3).

\section{Discussion}

Antenatal care is an indicator to measure the efficiency of maternal care utilization. It helps in preventing adverse pregnancy outcomes when provided early in the pregnancy and continued through delivery. Identification of problems in pregnancy results in early referrals for women with complications; this is particularly true in Ethiopia, where three-quarters of the population live in rural areas. So as this study focused on determinants of the number of Antenatal care visits in rural Ethiopia using the multilevel negative binomial analysis to estimate individual, household, community-level factors.

The current study estimated that $27.3 \%$ of pregnant women in rural Ethiopia have been received at least four ANC during their pregnancy. It showed an improvement as compared to the 2011 data which was a $47 \%$ increase. $^{40}$ This increment might be due to awareness creation activities, health promotion, and an increase in the number of health institutions and health care providers in rural areas. $^{41}$

In this study, individual-level and community-level factors were responsible for around $75 \%$ of the difference in the frequency of ANC visits during pregnancy in rural Ethiopia. After adjusting all factors, the frequency of ANC visits was higher among those pregnant mothers in the age range of 25 to 29 years, higher educational status of women and their partner, highest wealth quintile, women who had the autonomy to decide their health care, and community level literacy. However, women who had a higher birth order child and women from low socioeconomic status of the community had a lower frequency of ANC visits.

The current study showed that women who were in the age group of 25-29 years were 13 percentage points more likely to visit health institutions for ANC services compared with those who were in the age group of 15-24 
Table 3 Multi-Level Negative Binomial Regression on the Number of Antenatal Care Among Women Who Gave Birth Within the Last Five Years Preceding the Survey in Rural Ethiopia, EDHS 2016, 2020

\begin{tabular}{|c|c|c|c|c|}
\hline Variables & Category & CIRR $(95 \% \mathrm{Cl})$ & Full Model (AIRR (95\% Cl)) & P-value \\
\hline Age of women & $\begin{array}{l}15-24 \\
25-29 \\
30-49\end{array}$ & $\begin{array}{l}\text { I } \\
\text { I.03(0.95,I.I3) } \\
0.85(0.77,0.92)\end{array}$ & $\begin{array}{l}\text { I } \\
\text { I.13 (1.02, I.26) } \\
1.04(0.91,1.19)\end{array}$ & $\begin{array}{l}0.005 \\
0.320\end{array}$ \\
\hline Educational status of women & $\begin{array}{l}\text { No education } \\
\text { Primary } \\
\text { Secondary } \\
\text { Above }\end{array}$ & $\begin{array}{l}\text { I } \\
\text { I.29(I.I9,I.40) } \\
\text { I.48(I.30,I.69) } \\
\text { I.84(I.62,2.09) }\end{array}$ & $\begin{array}{l}\text { I } \\
1.19(1.08,1.32) \\
1.30(1.08,1.55) \\
1.35(1.07,1.71)\end{array}$ & $\begin{array}{l}<0.001 \\
<0.001 \\
0.003\end{array}$ \\
\hline Educational status of Husband & $\begin{array}{l}\text { No education } \\
\text { Primary } \\
\text { Secondary } \\
\text { Above }\end{array}$ & $\begin{array}{l}\text { I } \\
\text { I.26(I.I6, I.37) } \\
\text { I. } 46(I .31,1.63) \\
\text { I.44(I.24, I.66) }\end{array}$ & $\begin{array}{l}\text { I } \\
1.16(1.05,1.28) \\
1.22(1.08,1.38) \\
1.05(0.83,1.32)\end{array}$ & $\begin{array}{l}0.001 \\
0.002 \\
0.621\end{array}$ \\
\hline Occupational status of women & $\begin{array}{l}\text { No work } \\
\text { Agriculture } \\
\text { Non-agriculture }\end{array}$ & $\begin{array}{l}\text { I } \\
1.02(0.92,1.14) \\
1.13(1.01,1.26)\end{array}$ & $\begin{array}{l}\text { I } \\
\text { I.10 (0.97, I.25) } \\
\text { I.I3(I.0I, I.27) }\end{array}$ & $\begin{array}{l}0.004 \\
0.049\end{array}$ \\
\hline Wealth status & $\begin{array}{l}\text { Poor } \\
\text { Middle } \\
\text { Rich }\end{array}$ & $\begin{array}{l}\text { I } \\
\text { I.II(I.0I,I.23) } \\
\text { I.27(I.I5,I.4I) }\end{array}$ & $\begin{array}{l}\text { I } \\
\text { I.08 }(0.96,1.21) \\
\text { I.I }(1.04,1.31)\end{array}$ & $\begin{array}{l}0.124 \\
0.004\end{array}$ \\
\hline Family size & $\begin{array}{l}<5 \\
5-10 \\
>10\end{array}$ & $\begin{array}{l}\text { I } \\
0.89(0.82,0.96) \\
0.93(0.70,1.25)\end{array}$ & $\begin{array}{l}\text { I } \\
\text { I.0I(0.9I, I.II) } \\
\text { I.05(0.72, I.54) }\end{array}$ & $\begin{array}{l}0.206 \\
0.998\end{array}$ \\
\hline Autonomy to the decision of health care & $\begin{array}{l}\text { No } \\
\text { Yes }\end{array}$ & $\mathrm{I}$ & I. & 0.003 \\
\hline Distance to a health facility & $\begin{array}{l}\text { Not a big problem } \\
\text { Big problem }\end{array}$ & $\begin{array}{l}1 \\
0.92(0.84,1.01)\end{array}$ & $\begin{array}{l}\text { I } \\
0.86(0.96,1.03)\end{array}$ & 0.072 \\
\hline Birth order & $\begin{array}{l}1 \\
2-5 \\
>5\end{array}$ & $\begin{array}{l}\text { I } \\
0.87(0.79,0.96) \\
0.74(0.67,0.82)\end{array}$ & $\begin{array}{l}\text { I } \\
0.88(0.79,0.99) \\
0.80(0.69,0.94)\end{array}$ & $\begin{array}{l}0.024 \\
0.001\end{array}$ \\
\hline Community-level literacy & $\begin{array}{l}\text { Lower } \\
\text { Higher }\end{array}$ & $\begin{array}{l}\text { I } \\
1.87(1.61,2.19)\end{array}$ & I. & $<0.001$ \\
\hline Community-level poverty & $\begin{array}{l}\text { Lower } \\
\text { Higher }\end{array}$ & $\begin{array}{l}\text { I } \\
0.54(0.46,0.63)\end{array}$ & $\begin{array}{l}\text { I } \\
0.77(0.64,0.92)\end{array}$ & 0.01 \\
\hline \multicolumn{3}{|l|}{ ICC (\%) } & $10.7 \%$ & \\
\hline PCV-Explained variation (\%) & & & 74.9 & \\
\hline
\end{tabular}

Abbreviations: CIRR, crude incidence rate ratio; AIRR, adjusted incidence rate ratio; Cl, confidence interval; I, reference group; SNNP, Southern nation, nationalities and peoples; Others, Catholic and traditional religion followers; Full model, model includes all variables; ICC, intra cluster correlation; PCV, percent change of variance.

years. This finding supports previous studies done in different countries ${ }^{6,42,43}$ that showed the positive association between ANC visits and increased age of women. This might be due to health conditions and birth complications are higher in older women who tend to demand more visits. But it is not in line with studies done in metropoli$\tan$ countries. $^{20}$
The finding of the study also indicated that women who had primary, secondary, and above secondary educational attainment were 19,30 , and 35 percentage points more likely to use ANC services as compared with those who had no education respectively. This finding is consistent with the study conducted in Ghana. ${ }^{6,24}$ The statistical relationship between the utilization of maternal health 
services and education is also well documented in a systematic review of 74 studies and Bangladesh. ${ }^{14,34}$ This indicates that the educational attainment of the women increases awareness of the need to access health services by frequent antenatal care visits. The primary and secondary educational status of the husband was also more likely to have a high frequency of ANC visits as compared to the non-educated husband. This finding supports that the high educational attainment of the husband influenced the frequency of ANC visits in sub-Saharan countries. ${ }^{14,34}$ This implied that educated partners may be more concerned with their pregnant wives and associated pregnancy complications.

Furthermore, the multilevel negative binomial estimation indicates that the wealth status of the household had a positive and significant effect on the frequency of ANC visits. The result showed that pregnant women in the richer household were more likely to have frequent ANC visits relative to those in the poorest household. This finding agreed with a study conducted in different countries in the world. ${ }^{6,8,34}$ But, the positive association does not vary by urban-rural settings in these studies. Thus, the results suggested household wealth status could be an important variable for antenatal care utilization. This might be since having a low economic status would mean having less money for transportation towards the health facility for utilization of ANC service. Another possible explanation could be women who belong to rich families usually have proper education, access to mass media than from poorer families.

Besides, the presence of women's autonomy in their health care was related to more antenatal care visits. This indicates the importance of women's empowerment, not only within the household but also in the community. Women empowerment leads to greater decision-making power concerning maternal health. Our findings are consistent with a previous research study conducted in Bangladesh, ${ }^{34}$ which revealed that women who decided about their medical care were more likely to receive professional antenatal care.

The current finding also showed that the birth order of the child influences the number of antenatal care visits. Having higher birth order child was negatively and significantly associated with the number of ANC visits. This finding agreed with a study done in Ghana. ${ }^{6}$ This implies that mothers with more previous birth experiences demand lesser visits, all other things being equal.
From community-level variables, literacy at the community level was a significant factor that determined the number of ANC visits. A high frequency of antenatal care visits was associated with literacy in a rural population. This result is in line with the study done in India. ${ }^{8}$

\section{Strengths and Limitations}

We used large population-based data with a large sample size, which is representative of all rural regions of Ethiopia. Furthermore, a count statistical analysis (multilevel Negative Binomial regression analysis) was applied for this study that allows the effects of each determinant on the frequency of ANC services efficiently. The novelty of this paper lies in the fact that we have modeled the determinants of the number of antenatal care services in rural Ethiopia using the most recent DHS. One significant point of departure of this study from previous studies on Ethiopia is the inclusion of only rural place of residence. Even though, the cross-sectional nature of the EDHS data, reports of this finding explained by incidence rate ratio. The temporal relationship could not be established based on these study findings. Ethiopian demographic and health surveys were questionnaire-based surveys and depend on the memory of the respondents, and as such, recall bias in the results might be a limitation for this study.

\section{Conclusion and Recommendations}

The level of antenatal care visits among women who gave birth within the last five years before the survey was low in rural Ethiopia. Our results also indicate that wealth status, age, women and partner educational status, the decision-making power of women to their health care, community-level poverty, and literacy are significant factors affecting the number of antenatal care in rural Ethiopia. Besides, birth order is inversely and significantly associated with the frequency of ANC visits. The findings of this report help policymakers and programmers to focus their programs and plan in rural parts of the country to enhance maternally and child health. Priority should be given to women and their partners of low educational status to get appropriate maternal and child health care service promotions. However, ANC service is provided for free, interventions have to be in place to improve the household wealth status since household wealth status still plays a major role in the frequency of ANC follow-up. 


\section{Abbreviations}

WHO, World Health Organization; ANC, antenatal care services; IRR, incidence rate ratio; EDHS, Ethiopia Demographic and Health Survey; CI, confidence interval; NB, negative binomial; PR, Poisson regression.

\section{Data Sharing Statement}

The datasets used and/or analyzed during the revised manuscript can be accessed from the corresponding author via email by contacting melkalem21@gmail.com.

\section{Ethics Approval and Consent to Participate}

Not applicable, because the data was collected by the performance monitoring and accountability 2020 (PMA2020)/Ethiopia survey project. Data were obtained from the DHS website (URL: www.dhsprogram.com) which complies with relevant data protection and privacy regulations.

\section{Consent for Publication}

Not applicable as there are no image or other confidentiality-related issues.

\section{Acknowledgments}

Our deepest gratitude goes to the Central statistical Agency for providing the data.

\section{Author Contributions}

All authors made substantial contributions to conception and design, acquisition of data, or analysis and interpretation of data; took part in drafting the article or revising it critically for important intellectual content; agreed to submit to the current journal; gave final approval of the version to be published; and agree to be accountable for all aspects of the work.

\section{Funding}

There is no funding to report.

\section{Disclosure}

The authors declare that they have no conflicts of interest for this work.

\section{References}

1. Ekabua J, Ekabua K, Njoku C. Proposed framework for making focused antenatal care services accessible: a review of the Nigerian setting. ISRN Obstet Gynecol. 2011;2011(December):1-5. doi:10.5402/2011/253964

2. Sylvia Patience NT. Basic antenatal care approach to antenatal care service provision. Selected Topics Midwifery Care. 2019;1-14.

3. Picco S, Villegas L, Tonelli F, et al. Basic antenatal Care approach to antenatal care service provision. Web Sci. 2016;13.

4. Health R, Health A. WHO Guideline on Antenatal Care (2016). Dev Guideline. 2016;1-46.

5. Otundo Richard M. WHO Recommendations on Antenatal Care for a Positive Pregnancy Experience in Kenya. SSRN Electronic $J$. 2019;7(2):1-16.

6. Nketiah-Amponsah E, Senadza B, Arthur E. Determinants of the utilization of antenatal care services in developing countries: recent evidence from Ghana. African J Economic Management Stud. 2013;4 (1):58-73. doi:10.1108/20400701311303159

7. A-z CL. Antenatal Care in Developing Countries. Promises, Achievements and Missed Opportunities: an Analysis of Trends, Levels and Differentials, 1990-2001. WHO Lib Cataloguing Publication Data Antenatal. 2003;1-32.

8. Chandhiok N, Dhillon BS, Kambo I, Saxena NC. Determinants of antenatal care utilization in rural areas of India: a cross-sectional study from 28 districts (An ICMR task force study). $J$ Obstetrics Gynecology India. 2006;56(1):47-52.

9. Tovar LM. Individual and local level factors and antenatal care use in Colombia: a multilevel analysis. Cad Saúde Pública. 2014;30 (5):1079-1092. doi:10.1590/0102-311X00073513

10. Kistiana S. Socio-Economic and Demographic Determinants of Maternal Health Care Utilization in Indonesia. Environ Manage. 2009;2(2):212-219.

11. Neupane S, Doku DT. Determinants of Time of Start of Prenatal Care and Number of Prenatal Care Visits During Pregnancy Among Nepalese Women. J Community Health. 2012;37(4):865-873. doi:10.1007/s10900-011-9521-0

12. Kyei NNA, Campbell OMR, Gabrysch S. The Influence of Distance and Level of Service Provision on Antenatal Care Use in Rural Zambia. PLoS One. 2012;7:10. doi:10.1371/journal. pone. 0046475

13. Manithip C, Sihavong A, Edin K, Wahlstrom R, Wessel H. Factors associated with antenatal care utilization among rural women in Lao people's democratic republic. Matern Child Health J. 2011;15 (8):1356-1362. doi:10.1007/s10995-010-0671-y

14. Okedo-Alex IN, Akamike IC, Ezeanosike OB, Uneke CJ. Determinants of antenatal care utilization in sub-Saharan Africa: a systematic review. BMJ Open. 2019;9(10):1-14. doi:10.1136/bmjopen-2019-031890

15. Teshome MS, Meskel DH, Wondafrash B. Determinants of anemia among pregnant women attending antenatal care clinic at public health facilities in kacha birra district, southern Ethiopia. $J$ Multidiscip Healthc. 2020;13:1007-1015. doi:10.2147/JMDH.S259882

16. Amin R, Shah NM, Becker S. Socioeconomic factors differentiating maternal and child health-seeking behavior in rural Bangladesh: a cross-sectional analysis. Int $J$ Equity Health. 2010;9(1):1-11. doi:10.1186/1475-9276-9-9

17. Adamu YM, Salihu HM. Barriers to the use of antenatal and obstetric care services in rural Kano, Nigeria. J Obstet Gynaecol. 2002;22 (6):600-603. doi:10.1080/0144361021000020349

18. Petrou S, Kupek E, Vause S, Maresh M. Clinical, provider and sociodemographic determinants of the number of antenatal visits in England and Wales. Social Sci Med. 2001;52:1123-1134. doi:10.10 16/S0277-9536(00)00212-4 
19. Islam MM, Masud MS. Determinants of frequency and contents of antenatal care visits in Bangladesh: assessing the extent of compliance with the WHO recommendations. PLoS One. 2018;13(9):1-22. doi:10.1371/journal.pone.0204752

20. Beeckman K, Louckx F, Putman K. Determinants of the number of antenatal visits in a metropolitan region. BMC Public Health. 2010;10:1-9. doi:10.1186/1471-2458-10-527

21. Metgud CS, Katti SM, Mallapur AS. Wantamutte. Utilization Patterns of Antenatal Services Among Pregnant Women: a Longitudinal Study in Rural Area of North Karnataka. Al Ameen J Med Sci. 2009;2(1):58-62.

22. Visits A. Determinants of the number of Antenatal Visits in Somalia. BMC Pregnancy Childbirth. 2018;22.

23. Ousman SK, Mdala I, Thorsen VC, Sundby J, Magnus JH. Social determinants of antenatal care service use in Ethiopia: changes over 15 years. Front Public Health. 2019;7(JUN):1-10. doi:10.3389/ fpubh.2019.00161

24. Overbosch GB, Nsowah-Nuamah NNN, van den Boom GJM, Damnyag L. Determinants of antenatal care use in Ghana. J Afr Econ. 2004;13(2):277-301. doi:10.1093/jae/ejh008

25. Rurangirwa AA, Mogren I, Nyirazinyoye L, Ntaganira J, Krantz G. Determinants of poor utilization of antenatal care services among recently delivered women in Rwanda; a population-based study. BMC Pregnancy Childbirth. 2017;17(1):1-10. doi:10.1186/s12884017-1328-2

26. Manyeh AK, Amu A, Williams J, Gyapong M. Factors associated with the timing of antenatal clinic attendance among first-time mothers in rural southern Ghana. BMC Pregnancy Childbirth. 2020;20(1):1-7. doi:10.1186/s12884-020-2738-0

27. Shibre G, Zegeye B, Idriss-Wheeler D, Ahinkorah BO, Oladimeji O, Yaya S. Socioeconomic and geographic variations in antenatal care coverage in Angola: further analysis of the 2015 demographic and health survey. BMC Public Health. 2020;20:1-10. doi:10.1186/ s12889-020-09320-1

28. Mathe M. Socio-demographic factors affecting utilization of Antenatal Care Services in Botswana. Int $J$ Acad Res Business Social Sci. 2017;7:9. doi:10.6007/IJARBSS/v7-i9/3343

29. Aziz Ali S, Aziz Ali S, Feroz A, Saleem S, Fatmai Z, Kadir MM. Factors affecting the utilization of antenatal care among married women of reproductive age in the rural Thatta, Pakistan: findings from a community-based case-control study. BMC Pregnancy Childbirth. 2020;20(1):1-12. doi:10.1186/s12884-020-03009-4

30. Ergat Yarinbab T. Determinants of Antenatal Care Service Utilization during the First Trimester among Pregnant Women in Boke Woreda, Ethiopia: a Facility Based Unmatched Case Control Study. Curr Trends Biomed Eng Biosci. 2018;15(1):13-20. doi:10.19080/ CTBEB.2018.15.555904
31. Tusa BS, Weldesenbet AB, Kebede SA. Spatial distribution and associated factors of underweight in Ethiopia: an analysis of Ethiopian demographic and health survey, 2016. PLoS One. 2020;15 (12 December):e0242744. doi:10.1371/journal.pone.0242744

32. Gebremeskel F, Dibaba Y, Admassu B. Timing of First Antenatal Care Attendance and Associated Factors among Pregnant Women in Arba Minch Town and Arba Minch District, Gamo Gofa Zone, South Ethiopia. J Environ Public Health. 2015;2015:2015. doi:10.1155/ 2015/971506

33. 2016 CSA (CSA) [Ethiopia] and ICF. EDHS 2016. Addis Ababa, Ethiopia, and Rockville, Maryland, USA: CSA and ICF; 2017.

34. Bhowmik KR, Das S, Islam MA. Modeling the number of antenatal care visits in Bangladesh to determine the risk factors for reduced antenatal care attendance. PLoS One. 2020;15(1):1-17. doi:10.1371/ journal.pone.0228215

35. StataCorp. Stata Multilevel Mixed-Effects Reference Manual Release 14 [Internet]. Vol. 1, Statistical Software. 2015:720-766. Available from: https://www.stata.com/manuals14/me.pdf.

36. Merlo J, Chaix B, Ohlsson H, et al. A brief conceptual tutorial of multilevel analysis in social epidemiology: using measures of clustering in multilevel logistic regression to investigate contextual phenomena. J Epidemiol Community Health. 2006;60(4):290-297. doi:10.1136/jech.2004.029454

37. Antenatal care. Vol. 4, Bailliere"s clinical obstetrics and gynecology. 1990. p. 1-227.

38. World Health Organization. Antenatal Care Coverage: At Least Four Visits - Percentage. World Health Data Platform. 3-4. 2018.

39. Liyew AIDM, Tesema GIDA, Alamneh TS, et al. Prevalence and determinants of anemia among pregnant women in East Africa; A multi-level analysis of recent Demographic and Health Surveys. BMC Pregnancy Childbirth.2021.

40. Agency CS, Ababa A. Ethiopia Demographic and Health Survey. Int J Med. 2012.

41. Workie MS, Lakew AM. Bayesian count regression analysis for determinants of antenatal care service visits among pregnant women in Amhara regional state, Ethiopia. J Big Data. 2018;5(1). doi:10.1186/s40537-018-0117-8

42. Kupek E, Petrou S, Vause S, Maresh M. Clinical, provider and sociodemographic predictors of late initiation of antenatal care in England and Wales. BJOG. 2002;109(3):265-273. doi:10.1111/ j.1471-0528.2002.00524.x

43. Hildingsson I, Råoestad I, Waldenström U. Number of antenatal visits and women's opinion. Acta Obstet Gynecol Scand. 2005;84 (3):248-254. doi:10.1111/j.0001-6349.2005.00615.x
Journal of Multidisciplinary Healthcare

\section{Publish your work in this journal}

The Journal of Multidisciplinary Healthcare is an international, peerreviewed open-access journal that aims to represent and publish research in healthcare areas delivered by practitioners of different disciplines. This includes studies and reviews conducted by multidisciplinary teams as well as research which evaluates the results or conduct of such teams or healthcare processes in general. The journal covers a very wide range of areas and welcomes submissions from practitioners at all levels, from all over the world. The manuscript management system is completely online and includes a very quick and fair peer-review system. Visit http://www.dovepress.com/testimonials. php to read real quotes from published authors. 